\title{
Hospital Prevalence of Arterial Hypertension in the Cardiology Department of National Reference Teaching Hospital
}

\author{
Abdel-madjid Zakaria Zakaria ${ }^{1,}$, , Adam Ahamat Ali ${ }^{2}$, Foksouna Sakadi ${ }^{3}$, Allawaye Lucien ${ }^{1}$, \\ Toure Ali Ibrahim ${ }^{4}$ \\ ${ }^{1}$ Cardiology Department, Reference National Teaching Hospital, N'Djamena, Chad \\ ${ }^{2}$ Cardiology Department, Renaissance Teaching Hospital, N'Djamena, Chad \\ ${ }^{3}$ Neurology Unit, Reference National Teaching Hospital, N'Djamena, Chad \\ ${ }^{4}$ Cardiology Department, Amirou Boubacar Teaching Hospital, Niamey, Niger
}

\section{Email address:}

aboutingui2@gmail.com (Abdel-madjid Z.Z.), lucienallawaye14@gmail.com (Allawaye L.)

*Corresponding author

\section{To cite this article:}

Abdel-madjid Zakaria Zakaria, Adam Ahamat Ali, Foksouna Sakadi, Allawaye Lucien, Toure Ali Ibrahim. Hospital Prevalence of Arterial Hypertension in the Cardiology Department of National Reference Teaching Hospital. Cardiology and Cardiovascular Research.

Vol. 5, No. 2, 2021, pp. 74-77. doi: 10.11648/j.ccr.20210502.14

Received: March 8, 2021; Accepted: March 25, 2021; Published: May 21, 2021

\begin{abstract}
Introduction: Arterial hypertension is a frequent pathology in cardiology consultations in Chad. We report these observations with the aim of determining the prevalence of arterial hypertension in cardiological consultation at the National Reference University Hospital in N'Djamena. Methodology: We conducted an 8-month retrospective study from September 12, 2019 to April $16^{\text {th }}, 2020$, in the Cardiology Department of the National Reference Teaching Hospital. The variables studied were socio-demographic and clinical. Results: out of 352 patients seen, 121 met the selection criteria, ie a hospital prevalence of $34.34 \%$ with a female predominance. The average age was 64.5 years old with extremes ranging from 17 to 94 years old. Household were the most represented with $47.93 \%$ of cases. The most common antecedents were multiparity, arterial hypertension during pregnancy, hyperuricemia with respectively $21,48 \%$ then $4.95 \%$ for each of the last two. The most common associated cardiovascular risk factors (FDRCV) were obesity and diabetes with $13.22 \%$ and $6.61 \%$. Grade III systolic hypertension was the most represented with $33.05 \%$ as well as grade III diastolic hypertension with $32.23 \%$ of cases. Conclusion: Hypertension is a public health problem in Chad. Hospital prevalence has almost tripled in 26 years in the same department.
\end{abstract}

Keywords: High Blood Pressure, Prevalence, Chad

\section{Introduction}

High blood pressure is a major public health problem. Formerly known as a disease of the West, it also affects developing countries [1-4]. In Africa, its prevalence varies between 20 and 30\% [5-8]. It affects all races, ethnicities and socio-professional layers [2]. Called the silent killer, hypertension causes frequent and serious complications. Support is expensive and often poorly followed. We report these observations with the aim of determining the prevalence of arterial hypertension in cardiological consultation at the National Reference University Hospital in N'Djamena.

\section{Methodology}

This was an 8-month descriptive cross-sectional study from September 2019 to April 2020 carried out in the cardiology department of the National Reference Teaching Hospital. Were included in the study, all the patients seen in consultation during the period, having agreed to participate in the study and who were declared hypertensive according to 
the WHO criteria. The variables studied were sociodemographic (age, sex, origin, profession) and clinical (history, associated cardiovascular risk factors, reason for consultation, systolic and diastolic blood pressure). The data were entered and analyzed using office 2010 software and EPI info 3.5.3.

\section{Result}

Out of 352 patients consulted, 121 of them met the selection criteria, for a hospital prevalence of $34.34 \%$. The mean age of the patients was 64.5 years old with ranges of 17 and 94 years. The most common age groups were $60-79$ years old, 40 - 59 years old and 80 - 89 years old with respectively $31.40 \%, 28.09 \%$ and $27.27 \%$ (Table 1 ). The male / female sex ratio was 0.77 with a female predominance (Figure 1). The majority of our patients were in the Chadian capital with $74.43 \%$ (Figure 2). Women households and traders were the most represented with $47.93 \%$ and $9.9 \%$ (Table 2) The most common antecedents were multiparity, arterial hypertension during pregnancy, hyperuricemia with respectively $21,48 \%$ then $4.95 \%$ for each of the last two (Table 3). Among the associated cardiovascular risk factors, obesity and diabetes were the most common with $13.22 \%$ and $6.62 \%$ (Table 4). Dyspnea, palpitations, and headaches were the most frequently reported as a reason for consultation, with $14.87 \%, 13.22 \%$ and $9.91 \%$ respectively (Table 5). Grade III hypertension was the most common in systolic arterial hypertension with $33.05 \%$ of cases (Table 6). Among the diastolic hypertensive patients, $32.23 \%$ were grade III (Table 7).

Table 1. Distribution of patients by age group.

\begin{tabular}{lll}
\hline Age range & Patient & Percentage (\%) \\
\hline 0 - 20 years old & 3 & 2.4 \\
20 -39 years old & 13 & 10.74 \\
$40-59$ years old & 34 & 28.09 \\
$60-79$ years old & 38 & 31.40 \\
$80-99$ years old & 33 & 27.27 \\
Total & 121 & 100 \\
\hline
\end{tabular}

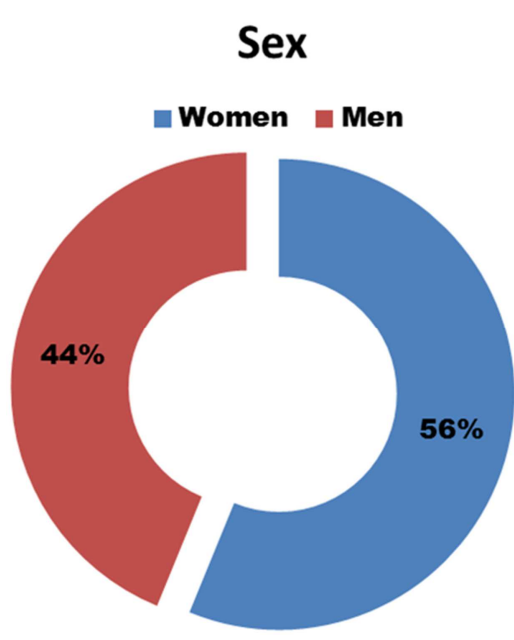

Figure 1. Distribution of patients by gender.
Table 2. Distribution of patients by profession.

\begin{tabular}{lll}
\hline Profession & Patients & Percentage (\%) \\
\hline Municipal agent & 1 & 0.82 \\
Veterinary agent & 1 & 0.82 \\
Butcher & 1 & 0.82 \\
Driver & 2 & 1.65 \\
Trader & 12 & 9.9 \\
Farmer & 8 & 6.61 \\
Student & 6 & 4.96 \\
Breeder & 1 & 0.82 \\
Teacher & 4 & 3.33 \\
Contractor & 1 & 0.82 \\
Official & 3 & 2.47 \\
Refrigeration engineer & 1 & 0.82 \\
Engineer & 1 & 0.82 \\
Marabout & 1 & 0.82 \\
Household & 58 & 47.93 \\
Carpenter & 2 & 1.65 \\
Military & 4 & 3.33 \\
Restorer & 1 & 0.82 \\
Tailor & 2 & 1.65 \\
Technician & 1 & 0.82 \\
Unemployed & 10 & 8.26 \\
Total & 121 & 100 \\
\hline
\end{tabular}

Table 3. Distribution of patients according to history.

\begin{tabular}{|c|c|c|c|}
\hline History & & patients & Percentage $(\%)$ \\
\hline \multirow[t]{19}{*}{ Medical } & Asthma & 1 & 0.82 \\
\hline & Stroke & 3 & 2.47 \\
\hline & Prostate cancer & 1 & 0.82 \\
\hline & Dilated Cardiomyopathy & 1 & 0.82 \\
\hline & Functional colopathy & 1 & 0.82 \\
\hline & Pulmonary fibrosis & 1 & 0.82 \\
\hline & Anorectal fistula & 1 & 0.82 \\
\hline & Hyperuricemia & 6 & 4.95 \\
\hline & Hemorrhoid & 2 & 1.65 \\
\hline & Hepatitis B & 1 & 0.82 \\
\hline & Heart failure & 1 & 0.82 \\
\hline & Renal failure & 2 & 1.65 \\
\hline & Goitre & 1 & 0.82 \\
\hline & Peptic ulcer & 4 & 3.30 \\
\hline & Peptic esophagitis & 1 & 0.82 \\
\hline & Pulmonary tuberculosis & 2 & 1.65 \\
\hline & HIV & 1 & 0.82 \\
\hline & Parkinson's & 1 & 0.82 \\
\hline & Psychiatric disorderS & 1 & 0.82 \\
\hline \multicolumn{4}{|l|}{ Surgical } \\
\hline & Lithotomy & 1 & 0.82 \\
\hline & myomectomy & 1 & 0.82 \\
\hline & Thyroid cystectomy & 1 & 0.82 \\
\hline \multicolumn{4}{|c|}{ Obstetrical } \\
\hline & Eclampsia & 1 & 0.82 \\
\hline & Pregnancy hypertension & 6 & 4.95 \\
\hline & Multiparous & 26 & 21.48 \\
\hline
\end{tabular}

Table 4. Distribution of patients according to the associated cardiovascular risk factors.

\begin{tabular}{lll}
\hline Associeted cardiovascular risk factors & Patient & Percentage (\%) \\
\hline Diabetes & 8 & 6.61 \\
Tobacco & 3 & 2.47 \\
Alcohol & 1 & 0.82 \\
Obesity & 16 & 13.22 \\
Nothing & 93 & 76.86 \\
Total & 121 & 100 \\
\hline
\end{tabular}




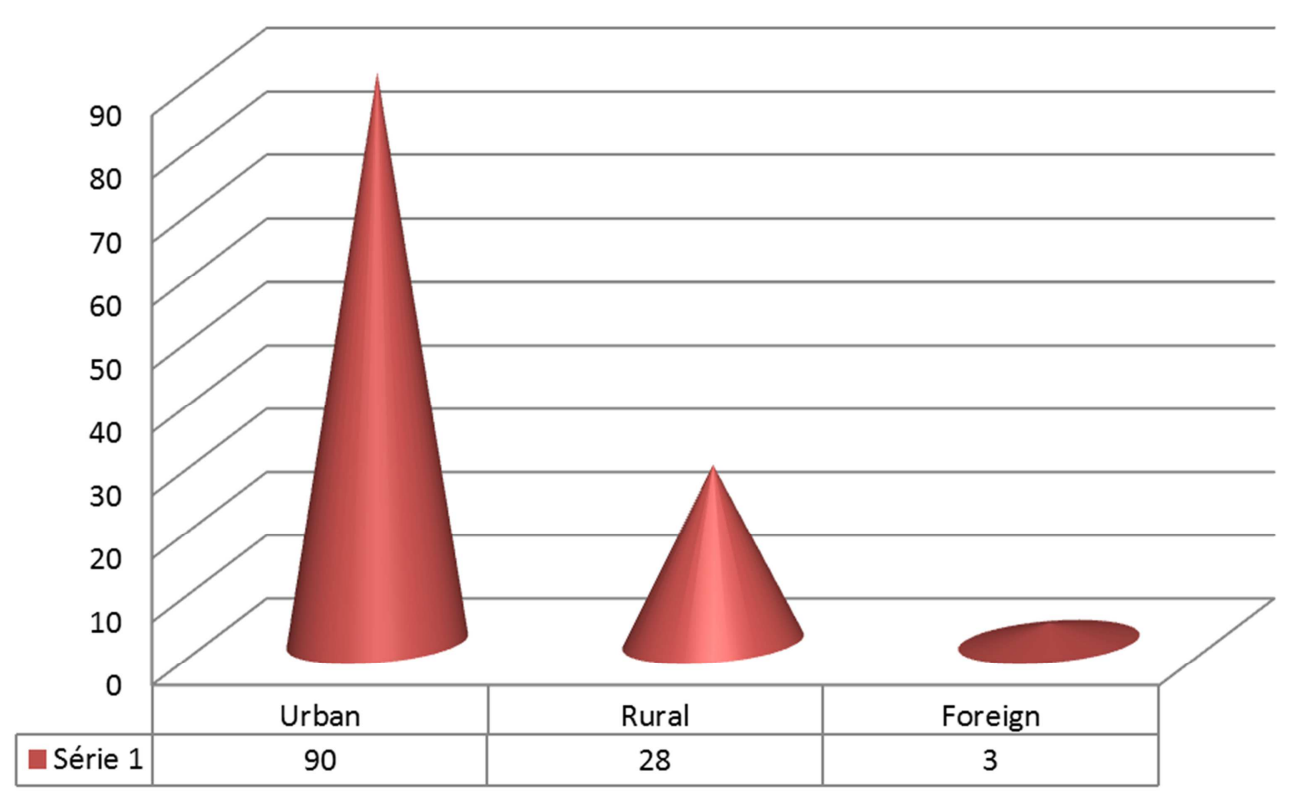

Figure 2. Distribution of patients according to dwelling place.

Table 5. Distribution of patients according to the reason for consultation.

\begin{tabular}{lll}
\hline Motif de Consultation & Patients & Percentage (\%) \\
\hline Anxiety & 1 & 0.82 \\
Ascites & 1 & 0.82 \\
Preoperative assessment & 2 & 1.65 \\
Headache & 12 & 9.91 \\
Headache + tinnitus & 1 & 0.82 \\
Headache + visual blurring & 3 & 2.47 \\
Headache + visual blurring + dizziness & 7 & 5.78 \\
Headache + dizziness & 5 & 4.13 \\
Headache + anxiety & 1 & 0.82 \\
Headache + tinnitus + dizziness & 6 & 4.95 \\
Headache + palpitation & 6 & 4.95 \\
Headache + dizziness + palpitation & 2 & 1.65 \\
Headache + cough & 1 & 0.82 \\
Cardiomegaly & 3 & 2.47 \\
Chest pain & 1 & 0.82 \\
Dyspnea & 18 & 14.87 \\
Epigastralgia & 2 & 1.65 \\
Visual blur & 1 & 0.82 \\
Hyperglycemia & 1 & 0.82 \\
Generalized edema & 6 & 4.95 \\
Palpitation & 16 & 13.22 \\
Polyarthragia & 1 & 0.82 \\
Maternity referral & 3 & 2.47 \\
HTA monitoring & 16 & 13.22 \\
Cough & 3 & 2.47 \\
Dizziness & 1 & 0.82 \\
Vomiting & 1 & 0.82 \\
Total & 121 & 100 \\
\hline
\end{tabular}

Table 6. Distribution of patients according to systolic blood pressure.

\begin{tabular}{lll}
\hline Systolic hypertension & Patient & Percentage (\%) \\
\hline No Hypertension & 5 & 4,13 \\
Grade 1 & 38 & 31.40 \\
Grade 2 & 38 & 31.4 \\
Grade 3 & 40 & 33.05 \\
Total & 121 & 100 \\
\hline
\end{tabular}

Table 7. Distribution of patients according to diastolic blood pressure.

\begin{tabular}{lll}
\hline Diastolic hypertension & Patient & Percentage (\%) \\
\hline No Hypertension & 21 & 17.35 \\
Grade 1 & 28 & 23.14 \\
Grade 2 & 33 & 27.27 \\
Grade 3 & 39 & 32.23 \\
Total & 121 & 100 \\
\hline
\end{tabular}

\section{Discussion}

We report a hospital hypertension prevalence of $34.34 \%$ over a period of 8 months. DAMOROU F. J. M in Togo in 2008 found a hospital prevalence of $22 \%$ of cases. [9] MOUANODJI M. found a prevalence of $12 \%$ in 1993 , at the Cardiology department of the National Reference Teaching Hospital. [10] Over a 26-year interval, hospital prevalence in Chad has increased by about $200 \%$ of cases compared to data from MOUANODJI M. This could be explained by the epidemiological transition experienced by African countries. The average age was estimated to be 64.5 years with extremes ranging from 17 to 94 years old. DAMOROU F. J. $\mathrm{M}$ and MOUNODJI $\mathrm{M}$. had respectively found a mean age of $53.48 \pm 15.02$ years old and 45.3 years old. The female sex represented $56.19 \%$ against $43.80 \%$ of the men, with a sex ratio of 0.77 . The majority of our respondents came from the city of N'Djamena, which represented $74.43 \%$ of cases. $47.93 \%$ of our respondents were households. Obesity was only $13.22 \%$ in our patients, although lower than the figures in the literature. DAMOUROU F. J. M. had regained an obesity rate of $56.8 \%$. DENOLLE in France in its series of 5,136 patients and TWAGIRUMUKIZA in its study of 144 cases had also found rates of $52 \%$ and $54.9 \%$ respectively in $2001[11,12]$. On the other hand, CHAMONTIN in France for 3 months out of 156,470 cases and KOFFI in Côte d'Ivoire on a sample of 220 cases found frequencies of $30 \%$ 
and $41.6 \%$ respectively $[13,14]$. This difference is explained by the fact that the latter assessed obesity according to BMI greater than $30 \mathrm{Kg} / \mathrm{m}^{2}$. The breakdown by sex showed us that women were more obese than men in a proportion of $71.7 \%$ against $37.6 \%$. The association between diabetes and arterial hypertension was found in $6.61 \%$ of patients. Our results were similar to those found by MORGENSEN in the USA in 2003 in his study on 457 patients and DONELLE in France in 2001 in a series of 5246 patients, who found $7.5 \%$ and $8 \%$ respectively $[15,11]$. In our study, $14.87 \%$ of our patients had dyspnea as a reason for consultation, 33\% had grade 3 systolic arterial hypertension and $32 \%$ of our respondents had grade 3 diastolic arterial hypertension.

\section{Conclusion}

High blood pressure is a public health problem in developing countries, especially in Chad, a country which, like other African countries, is currently experiencing an epidemiological transition. Thus, the prevalence of hypertension has almost tripled in 26 years in the same department of Cardiology. This is why a large multicenter study is needed to detect and manage so many patients in order to avoid complications.

\section{References}

[1] OPAL S. Arterial hypertension, In CECIL: Treated on internal medicine. Paris, Flammarion. 251-71.

[2] NATIONAL HEALTH ACCREDITATION AND EVALUATION AGENCY. Management of patients with high blood pressure. ANAES Report: April 2001.

[3] KRZESINSKI J. New American and European directives in 2003 for the management of arterial hypertension, Revue Médicale de Liège 2003; 58: 563-571.

[4] COOPER R., ROTMI C., ATAMA S., Mc GEE D., OSOTIMEHIN B. The prevalence of hypertension in developing nations in seven population of west African origin. Am j public health 1997; 87: 160-8.

[5] SEEDAT YK. Hypertension developing nations in subSaharan Africa. J Human hypertensions 2000; 14: 739-47.

[6] NAICKER S. END Stage renal disease in sub-Saharan and South Africa. Kidney int Suppl. Févier 2003; 83: S 119-22.

[7] AUBRY P. The Evolution of Cardiovascular Diseases in Developing Countries: Tropical Medicine 2003; 96: S 11-5.

[8] BERTRAND E. Arterial hypertension in sub-Saharan Africa and the value of low-dose combination therapy with diuretics and reserpine. Laboratoires Lisa Pharm juillet 2004; 89: 51-5.

[9] DAMOROU F., TOGBOSSI E., S. PESSINABA B., SOUSSOU epidemiology and circumstances of discovery of arterial hypertension (hypertension) in hospitals in kpalime (secondary city of togo). Medical mali 2008; TOME XXIII; 4: $17-20$.

[10] MOUANODJI M. Epidemiological, clinical and evolutionary aspect in a hospital environment in N'Djamena in relation to 118 cases. Med. Afrique noire journal 1996; 43: 580-84.15.

[11] DENOLLE T. Therapeutic decision according to the cardiovascular risk in systolic hypertension isolated in general medicine. Arch. Maladies du cœur et des vaisseaux 2001; 95 $16-6$.

[12] TWAGIRUMUKIZA M. Aspects of hypertension in the internal medicine department at Burare-Rwanda CHU: prospective study of 144 cases. Médecine d'Afrique Noire 2003; 50: 167-175.

[13] CHAMONTIN B. High blood pressure is the most common risk factor among general practice consultants. Arch. Maladies du cœur et des vaisseaux 2001; 95: 44-3.

[14] KOFFI N M, SALLY SJ, KOUAME P, SILUE K. Facies of HT in the workplace at the Autonomous Port of Abidjan in CI. Prospective study on 220 cases. Médecine d'Afrique noire 2001; 50: 54-3.

[15] MORGENSEN E. Effect of the combination of perindopril and indapamide on albuminuria in diabetes. Journal of the American Heart Association 2005, page 1063. 